\title{
Developing the Informational and Digital Environment of a University: Problem Analysis and Assessment
}

\author{
Gulnara M. Kvon ${ }^{1 *}$, Vera B. Vaks ${ }^{2}$, Aydar M. Kalimullin ${ }^{3}$, Almira R. Bayanova ${ }^{3}$, \\ Albina R. Shaidullina ${ }^{4}$, Anzhela V. Dolzhikova ${ }^{5}$, Natalia I. Lapidus ${ }^{6}$ \\ ${ }^{1}$ Ural State University of Economics, Yekaterinburg, RUSSIA \\ ${ }^{2}$ Kazan National Research Technical University named after A. N. Tupolev - KAI, Kazan, RUSSIA \\ ${ }^{3}$ Kazan (Volga region) Federal University, Kazan, RUSSIA \\ ${ }^{4}$ Almetyevsk State Oil Institute, Almetyevsk, RUSSIA \\ ${ }^{5}$ Peoples' Friendship University of Russia (RUDN University), Moscow, RUSSIA \\ ${ }^{6}$ I.M. Sechenov First Moscow Medical University (Sechenov University), Moscow, RUSSIA
}

Received 2 January 2019 - Revised 22 March 2019 - Accepted 3 April 2019

\begin{abstract}
The research objective is to reveal and analyze the problems in developing the informational environment of a university. The authors applied theoretical and empirical methods, such as observation, polling, composing a Likert scale, calculation of Spearman ranking correlation coefficients, tabular and diagram techniques of data visualization, etc., which enabled to achieve the set goal. The score method based on Likert scale enabled to reveal the problem aspects of forming the informational and digital environment of a university. Also, these techniques enabled to quantitatively assess each problem, assess their significance and reveal the degree of each factor's relation to each problem of using the information and communication technologies at a university. University professors were polled about using innovative information technologies in order to both enhance the education efficiency and apply new pedagogical concepts and techniques. The poll revealed the problem aspects impeding the development of the informational environment. The research results are presented as a series of diagrams, reliably characterizing the issues which the university professors face when implementing the educational process. Besides, a number of indicators were calculated to determine the correlation coefficients, which enabled to quantitatively assess the degree of correlation between the two series of the compared quantitative indicators. The research revealed the factors impeding the development of the informational environment of a university. Awareness of these factors by the university administration and teaching staff would allow overcoming them, with a view of increasing the quality of educational services. The authors are making a substantiated conclusion that, despite certain difficulties, the informational technologies integrated into the educational process comply with the modern requirements of the society and enhance the competencies of both the students and professors participating in the educational process.
\end{abstract}

Keywords: innovative processes, informational and digital environment, issues, higher education, educational process, Likert scale

(C) 2019 by the authors; licensee Modestum Ltd., UK. This article is an open access article distributed under the terms and conditions of the Creative Commons Attribution License (http://creativecommons.org/licenses/by/4.0/).

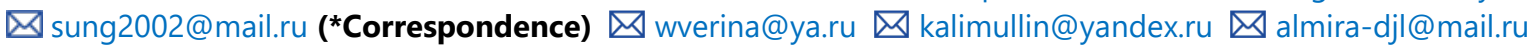




\section{Contribution of this paper to the literature}

- A list of questions with an interval scale was elaborated, which enabled to identify the problems impeding the development of the informational environment of a university.

- The problems which arise when using information and communication technologies and which are potentially capable of decreasing the quality of education at a university were analyzed and assessed. The assessment was carried out with statistical methods, using the rank correlation method.

- Spearman coefficients within the set limit were calculated, which allow assessing the significance of problems and determining the degree of correlation of each factor with each of the identified problems when using the modern innovative technologies at a university.

- To deepen the study and enhance its visualization, diagrams are built based on the carried out poll. The diagrams present the comprehensive assessment of the problems having a negative impact on the university professors' motivation for further using of modern technologies during the educational activity.

\section{INTRODUCTION}

\section{The Relevance of the Research}

Implementing informational and digital technologies in the modern educational process is an indispensable requirement for forming the competitive subjects of professional activity highly demanded in the labor market. Currently, the Russian Federation is implementing a priority project in the sphere of education "Modern Digital Educational Environment in the Russian Federation", adopted as a part of the state program "Development of education" for 2013-2020 and aimed at creating the necessary conditions for developing the educational environment under economy digitalization, which implies the complex of competencies in the subjects of professional activity. Elaboration of such a complex is impossible in the absence of a modernized system of education and professional training. Hence, the tasks of the project are as following: "to bring the educational programs in compliance with the needs of digital economy, to widely introduce the digital tools of learning activity and to comprehensively include them into the informational environment, and to provide opportunities for the citizens to study according to individual curricula during their lifetime - at any time and in any place" (Modern Digital Educational Environment in the Russian Federation, 2016).

Forming the full-fledged informational and digital environment of a university and using the innovative informational educational technologies in the educational process is an indispensable factor of the functioning of an educational institution. It is especially important both to broaden the use of informational and communicational technologies (ICT) and to implement the online learning techniques, as this would increase the quality of education. However, the online techniques and the lifelong learning implementation make it necessary to develop the modern conceptions in pedagogical science implying the enhanced role of students in the educational process; in particular, these are Andragogy, Heutagogy, Paragogy, Peeragogy, and Cybergogy. (These are 4 concepts shaping $21^{\text {st }}$ Century Learning, 2014). Each of these conceptions is oriented towards the specific features of a student. For example, Andragogy implies changing the approach to education as it is necessary to educate adults with a well-established system of knowledge, a clear motivation for studies, understanding of the goals of learning, and orientation towards solving specific personal tasks as a result of learning. Heutagogy is a concept of providing independence for a student in what regards the methods and objects of learning, its phenomena, and the processes studied. Paragogy presents conceptual bases for learning in groups through mutual creation and mastering of the educational content by students. Peeragogy focuses on the educational technique implying self-organization of student groups without a tutor. Cybergogy is the concept of mobile learning when the source of knowledge is both the tutor, educational and non-educational materials from online sources, and social interaction implemented both in the real world and online, in which a student participates at any moment of his/her life.

As these concepts play an increasingly eminent role in educational activity, the informational and digital environment of a university should undergo significant transformation, which inevitably causes problems in its developing and using both by tutors and students (Nikonorova \& Maminiva, 2018). Besides, the growth of requirements to tutors due to the complication of the educational process becomes another problem aspect. The tutors must act not only as a source of new knowledge but also as system administrators, organizing independent work of the students with both materials developed by professor and other materials and controlling it without directly interfering into the process of forming the required competencies by the students. 


\section{LITERATURE REVIEW}

Researching the problem of introducing information technologies into the educational environment of a university requires taking into account various factors, among which are the following: motivation of a professor and students, difficulties in perceiving the informational content when using information technologies, increased requirements to future graduates, etc. (Kondrateva, Madyakina \& Galiullina, 2018). The realities of professional activities today demand quality training at universities and understanding of modern technologies; in this regard, information technologies are one of the key aspects of educational activity at a higher educational institution.

Implementation of educational activity with special attention to students' motivation was considered in the work by Elikanida et al. (2018). The authors consider the professional motivation of university students as a set of needs, attitudes, and interests satisfied during the educational activity. Taking into account the importance of motivational factors when forming the student's personality, the authors developed a scientific and methodological resource for enhancing the students' motivation as a mechanism for studying the characteristics of professional activity.

The importance of introducing information technologies, viewed as an innovative component of the educational process at university, was shown in the works by Masalimova, Vaks, and Kvon (2018), Kvon and Vaks (2017). In the said papers, the authors review the features and advantages of introducing innovative educational technologies in the educational activity and their significance in forming the required competencies of the students. The aforementioned works show that the technologies oriented towards learning with modern means of digital communication facilitate developing a competitive specialist possessing the necessary qualities in compliance with the requirements of the modern economy.

Besides the traditional education techniques (lectures, practical sessions, oral tests, etc.), the innovative techniques in the educational process include elements of project learning and case techniques; the latter consist in presenting the teaching material to students in the form of professional problems, as shown in the work by Saygusheva (2013). The project learning technique allows developing target attitudes in students, projecting the content of education in compliance with the future professional requirements, forming the experience of creative activity, and facilitating full realization of the problems.

The features and problems of developing the informational environment to provide the modern state of educational process management are presented in the work by Kirilova et al. (2018). The authors see the features of developing the informational educational environment as a holistic system and demonstrate its influence on the changes in educational processes at a university. The authors use a certain period (5 years) to reveal and consider the changes associated with the transition to the competence approach. The new priorities in choosing the forms and techniques of learning with the development of the informational environment, in turn, lead to changes in the composition and structure of competences.

According to Munyengabe et al. (2019), transformation of pedagogical practice as a result of using ICT for increasing the quality of education and bringing it to compliance with the requirements of the new century, which provide forming the modern human potential, is the necessary aspect of forming the competitive economy. Its needs presuppose various skills in the subjects of professional activity, including adapting to changes and introducing innovations. However, the satisfaction of these needs requires specific development of human resources. Integration of ICT into all kinds of pedagogical activity is one of the means for such development. At the same time, it is necessary to research the role of ICT in training the subjects of professional activity; in particular, to assess how university professors perceive the ICT integration into pedagogical activity, what problems impede professors' motivation to use ICT in their work, and whether ICT enables the potential subjects of professional activity to acquire the necessary skills.

To maintain a student's involvement in the educational process, which ideally should continue during the whole period of the subject's professional life, it is necessary to consider the motives of the subjects of professional activity, participating in the educational processes as students, as well as to comprehend the problems facing the student. To that end, various educational techniques may be used, which allow improving the learning process. The key techniques are the ICT built into the educational process and used for independent work of students. The ability of a student to work independently, using the informational and digital environment of the university, facilitates the formation of the necessary skills and competencies for future professional activity. The issues of motivation were also considered in the work by Kvon, Vaks, and Pozdeeva (2018). In the said work, the authors, using the correlation analysis methods, study the factors enabling to identify the students' motivation to use innovative technologies in the educational process and perform independent work on their basis.

In this process, a professor is to render assistance during solving the student's tasks and to assess the efficiency of the student's actions. This is accompanied by technical difficulties, as the commonly used Online Homework Systems (OHSs) and Virtual Learning Environments (VLEs) offer tools for assessing the results of the asks solved by the students but do not allow interactive assessment of the solving process. This shows the potential for future 
development of the informational and digital environment at a university and the techniques applied by the professors. It is necessary to develop the Graphical User Interface (GUI), capable of tracking the students' actions (Traces) and analyzing them to assess the working process of the students. Such an assessment technique, proposed by Calvo et al. (2019), may correlate with more traditional methods of assessment.

At the same time, when using the independently developed techniques in the informational and digital environment of a university, it is necessary to assess the risk of decreasing the students' potential abilities to acquire new knowledge, which occurs due to insufficient training in the system of secondary education and limits the students' ability to comprehend and apply the innovative technologies developed by the university. Although the probability of such risk may be not very high, as shown in the work by Kvon et al. (2018), it is still very important, as the insufficient students' comprehension of the learning technologies and methods of fulfilling and assessing the tasks may lead to decrease of the educational process efficiency even in a quality informational and digital environment of a university.

This is why, according to Hsu and Shiu (2018), it is necessary to take into account that the presence of a tutor directly influences the formation and stability of skills and competencies in students. Thus, using the informational and digital environment of a university and various distant educational technologies does not relieve the professors of responsibility to develop, organize, promote, discuss and choose the learning direction in order to obtain the required results depending on the needs and abilities of their students (Nadreeva, 2018). As the same time, in most cases the professors play the leading role, setting the educational goals and required resources, providing access to informational resources and consultations in compliance with the goals set by them. Using the ICT by the professors when setting tasks allow the students to actively participate, thinking about the process of fulfilling the task, to develop the skills of independent activity and the techniques of independent assessment of their performance, which is impossible under the guidance of a tutor.

In order to implement an innovative approach to education, many Russian universities use the system of the electronic study support called Learning Management System (LMS). This system provides full-fledged access to the educational information and allows controlling the learning results both in the form of testing and assessing the practical and laboratory works, as well as analyzing the students' performance through built-in analytical reports. Another convenient feature of LMS is using a standard web-technology for education organization, which spares the necessity to purchase the special software. As research by Kvon and Vaks (2017) shows, the main feature of learning with LMS is independent management of the learning process by the student, as a student may fulfill the study tasks in the convenient time.

The use of online education technologies gave the educational activity a new impulse for development. Gutierrez (2014) connects that with the occurrence and active practical implementation of modern conceptions, in particular, Heutagogy, Peeragogy, and Cybergogy. Each of these conceptions is aimed at increasing the efficiency of learning of the educational process participants. Heutagogy allows independently finding one's own goals and methods of learning, using the opportunities provided by the virtual environment. Peeragogy implies a decentralized approach to learning without a tutor, while each member of a student group may take up the tutor functions. Cybergogy is based on the opportunity to withdraw from the traditional educational techniques. Learning is based on social interaction and can be implemented during communication, not obligatorily defined as an educational process.

\section{Purpose and Objectives of the Study}

The purpose of the research is to analyze the interaction between the process of forming the informational and digital environment of a university and the level of preparedness by university professors to use ICT in their professional activity, as well as to consider and analyze the factors being the problem aspects when forming the informational and digital environment of a university, based on university professors' opinions.

The research fulfills the following objectives:

1. To study and assess university professors' opinions on forming the informational and digital environment of a university and the problems arising during its formation.

2. To pose the problems that may influence the formation of the informational and digital environment of a university.

3. To analyze and characterize the impact of the problems, which arise during the formation of the informational and digital environment at a university, on the quality of the professors' performance, based on composing analytical matrices, in order to demonstrate the interconnection between the identified problem aspects and the efficient use of the informational and digital environment of a university, as well as of implementing the correlation analysis. 
4. To summarize the analysis results and to assess the interconnection between the identified problems and the efficient formation of the informational and digital environment of a university.

The analysis was carried out based on polling professors of several Russian universities and processing the obtained results.

\section{RESEARCH METHODOLOGY}

\section{Theoretical and Empirical Methods of Research}

The research methodology is one of its peculiar features, as it determines the process of obtaining the final results by the authors and allows assessing their significance. The consecutive application of the planned research techniques provides solving the set tasks and achieving the research objective. In most cases, the research process implies characterizing the specific and previously not studied aspects of the research object, as well as assessing and analyzing the changes in its functioning under the changed external conditions.

By the number of respondents, the present research belongs to the category of reconnaissance studies, as questionnaire-based polling was performed with a rather small number of respondents (182 people from the following Russian Universities and Institutions: Kazan National Technical University named after A.N. Tupolev KAI, Kazan (Volga region) Federal University, Almetyevsk State Oil Institute, Peoples' Friendship University of Russia, I.M. Sechenov First Moscow Medical University).

The research applied a complex of interconnected methods, each of which determined the structure and content of the research, as well as enabled to achieve its goal and provide the necessary results. The methods can be divided into theoretical and empirical ones. The theoretical methods include the method of problem setting and the method of analysis; the empirical methods are observation, polling (in the form of a questionnaire), summarizing, and assessment with an ordinal scale.

The compiled and processed data, as well as the statistical calculations of the certain aspects of forming the informational and digital environment of a university, which constitute the general research results, were presented in the form of diagrams vividly demonstrating the ordinal assessment of the degree of consent or disagreement of certain respondents with the opinions selected by the authors. The final analysis of the opinions allowed concluding that there is a strong relationship between each of the factors considered in the opinions, and the issues of forming the informational and digital environment of a university, as well as between the degree of their influence on the forming and using the informational and digital environment of a university within the educational process.

\section{Stages of Research}

When planning the research, the authors applied the method of the problem setting, which allowed formulating the research hypothesis, determining its goal and distinguishing the tasks. At the preliminary stage of the research, a list of questions for polling was developed; then, the questions were offered to potential respondents - professors of various Russian universities. After that, the method of analysis was used, which enabled to characterize the research object and to select the factors to be studied. Then, with the help of empirical methods, we assembled and processed the factual data in compliance with the research goal. The research implied the study of actually expressed opinions of the respondents; thus, the following empirical methods were to be used: observation, polling (with a questionnaire), summarization of polling results, and composing an ordinal scale of assessments, also called a Likert scale, which allows assessing the attitudes of the respondents to the studied problem. This method yields quantitative assessments of the respondents' attitudes, which can be used to analyze the degree of interest in the studied aspects, measured with a ranking scale (Marutsak, 2015). In practice, the ordinal scale is used for the respondents expressing their consent or disagreement with the offered opinions characterizing the research object, which are then analyzed. The research results with the ordinal scale of assessments were processed with the Spearman ranking correlation coefficients, which allowed to characterize the practical dependence between the factors distinguished by the authors and the professors' preparedness for forming and using the informational and digital environment of a university in their professional activity.

At the final stage of the research, the authors summarized and analyzed the obtained results and formulated conclusions based on them.

\section{RESULTS}

After identifying the research problem and summarizing the theoretical basis, we carried out the research to reveal the specific aspects impeding the introduction of information technologies. This study focuses on university 
Table 1. Ranking of results for each question

\begin{tabular}{cccccc}
\hline & \multicolumn{5}{c}{ Answers and assessment in points } \\
\cline { 2 - 5 } Question & Fully agree & Rather agree & $\begin{array}{c}\text { Have not thought } \\
\text { about it }\end{array}$ & Rather disagree & Disagree \\
\cline { 2 - 5 } & 5 points & 4 points & 3 points & 2 points & 1 point \\
\hline 1 & & & \\
\hline 2 & & & & \\
\hline$\ldots$ & & & & \\
\hline
\end{tabular}

teaching staff from the viewpoint of their perception of information technologies and readiness (as well as capability and opportunity) to work with them.

We have developed a questionnaire aimed at clarifying the attitudes of the professors to the aspects impeding, in our opinion, their work in the informational and digital environment of a university during the educational process.

The following questions were posed:

Do you agree with the following statement? To what extent is it correct?

1. It is necessary to develop a system of motivation of professors to place their materials in the informational environment of a university and use it in the educational process.

2. It is necessary to comparatively assess the quality of the content uploaded to the informational environment of a university by different professors, as otherwise the professors would not be motivated for improving it.

3. It is necessary to protect the materials placed in the informational environment of a university from their unauthorized use, in order to register the author's contribution to their development.

4. Fulfilling tasks by students distantly in the informational environment of a university makes their checking easier for a tutor and causes no difficulties when assessing the quality of learning and giving marks.

5. There is a psychological problem of professors' unpreparedness for innovations introduced in the informational environment of a university, which decreases the quality of the educational process as a whole.

The questionnaire consists of five questions, each implying answers in a range from complete disagreement (1 point) to complete consent (5 points). These measuring scales are numerous, with various numbers of assessments; we used the standard scale (Dubina, 2006) and offered the following answers to the set questions (Table 1).

The questioning comprised 182 professors of such Russian universities as Kazan National Technical University named after A.N. Tupolev - KAI, Kazan (Volga region) Federal University, Almetyevsk State Oil Institute, Peoples' Friendship University of Russia, I.M. Sechenov First Moscow Medical University.

When processing the results, we used the algorithm proposed in the work by Kvon, Vaks, and Pozdeeva (2018), which allows assessing the problems arising during the educational process.

The work with the polling results implies the following stages:

1. General processing of the results and analysis of the percentage distribution of answers for each question.

2. Graphic visualization of the answers.

3. Compiling the summary table with polling results.

4. Processing the results using statistical methods.

5. Calculating the Spearman ranking correlation coefficient.

6. Interpretation of the results.

Below we present the research results in more detail.

\section{Stage 1. General Processing of the Results and Analysis of the Percentage Distribution of Answers for Each Question}

This stage was of special interest, as it allows identifying the general character of professors' answers to the set questions.

The answers were distributed as shown in Table 2. 
Table 2. Results of summary distribution of the professors' answers to the set questions

\begin{tabular}{|c|c|c|c|c|c|c|}
\hline \multirow{2}{*}{ Answers } & \multirow{2}{*}{$\begin{array}{l}\text { Points for } \\
\text { the answer }\end{array}$} & \multicolumn{5}{|c|}{ Questions } \\
\hline & & I & II & III & IV & $\mathbf{V}$ \\
\hline Fully agree & 5 & 109 & 49 & 105 & 28 & 47 \\
\hline Rather agree & 4 & 56 & 60 & 47 & 49 & 54 \\
\hline Have not thought about it & 3 & 11 & 39 & 17 & 11 & 11 \\
\hline Rather disagree & 2 & 4 & 15 & 2 & 73 & 43 \\
\hline Disagree & 1 & 2 & 19 & 11 & 21 & 28 \\
\hline Number of respondents & & 182 & 182 & 182 & 182 & 182 \\
\hline Total points & & 812 & 651 & 779 & 535 & 595 \\
\hline
\end{tabular}

Table 3. Percentage distribution of the answers

\begin{tabular}{lccccc}
\hline \multirow{2}{*}{ Answers } & \multicolumn{5}{c}{ Questions } \\
\cline { 2 - 6 } & I & II & III & IV & V \\
\hline Fully agree & 60 & 27.1 & 57.6 & 15.3 & 25.9 \\
\hline Rather agree & 30.6 & 32.9 & 25.9 & 27 & 29.4 \\
\hline Have not thought about it & 5.9 & 21.2 & 9.4 & 5.9 & 5.9 \\
\hline Rather disagree & 2.3 & 8.2 & 1.2 & 40 & 23.5 \\
\hline Disagree & 1.2 & 10.6 & 5.9 & 11.8 & 15.3 \\
\hline Total: & 100 & 100 & 100 & 100 & 100 \\
\hline
\end{tabular}

The total number of points was determined by the sum of the products of the number of professors choosing the corresponding answer. This indicator is necessary for further processing of the results and compiling the summary table with the data for each professor.

The percentage of the obtained results is shown in Table 3.

The results in Table 3 show a high significance of the motivational factor for the professors. It reflects their opinion on the necessity of additional stimulation of working with information technologies, as working in the informational environment demands more time and effort (results of processing the answer to question 1 - "It is necessary to develop a system of motivation of professors to place their materials in the informational environment of a university and use it in the educational process").

If the positive answers ("fully agree" and "rather agree") are to be combined, the significance of motivation was recognized by $90.6 \%$ of the total number of professors.

Also, the significance of question 3 ("It is necessary to protect the materials placed in the informational environment of a university from their unauthorized use, in order to register the author's contribution to their development") appeared to be very high. The total of $83.5 \%$ of the professors (57.6 and $25.9 \%)$ agree that it is necessary to protect the copyright of the materials uploaded by the tutors to the commonly accessed system.

\section{Stage 2. Graphic Visualization of the Answers}

Graphic visualization allows revealing the overall character of the answers and demonstrates the polling results, reflecting the opinions of the professors.

Figures 1-5 show the polling results in percent. 
Question 1. It is necessary to develop a system of motivation of professors to place their materials in the informational environment of a university and use it in the educational process

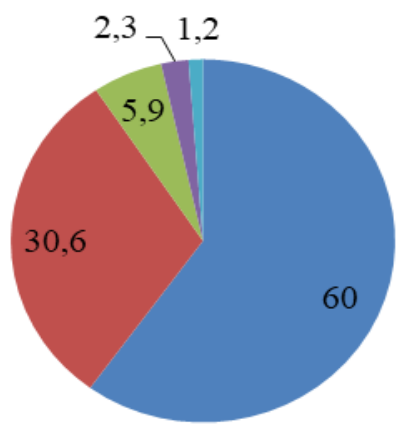

- Fully agree

nather agree

- Have not thought about it

Eather disagree

Disagree

Figure 1. Polling results for question 1

\section{Question 2. It is necessary to comparatively assess} the quality of the content uploaded to the informational environment of a university by different professors, as otherwise the professors would not be motivated for improving it

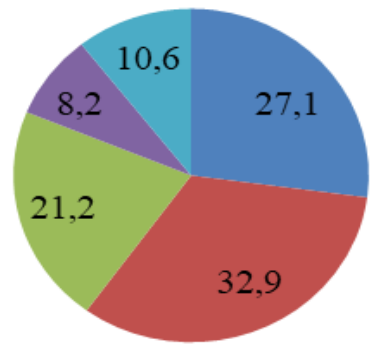

Fully agree

Rather agree

- Have not thought about it

- Rather disagree

Disagree

Figure 2. Polling results for question 2

Question 3. It is necessary to protect the materials placed in the informational environment of a university from their unauthorized use, in order to emphasize the author's contribution to their development

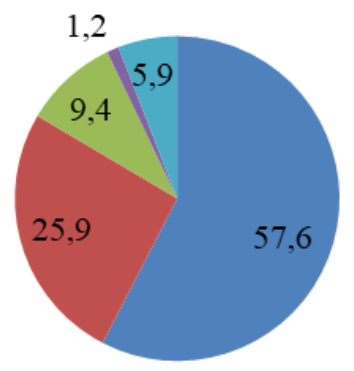

- Fully agree

- Rather agree

- Have not thought about it

- Rather disagree

- Disagree

Figure 3. Polling results for question 3 


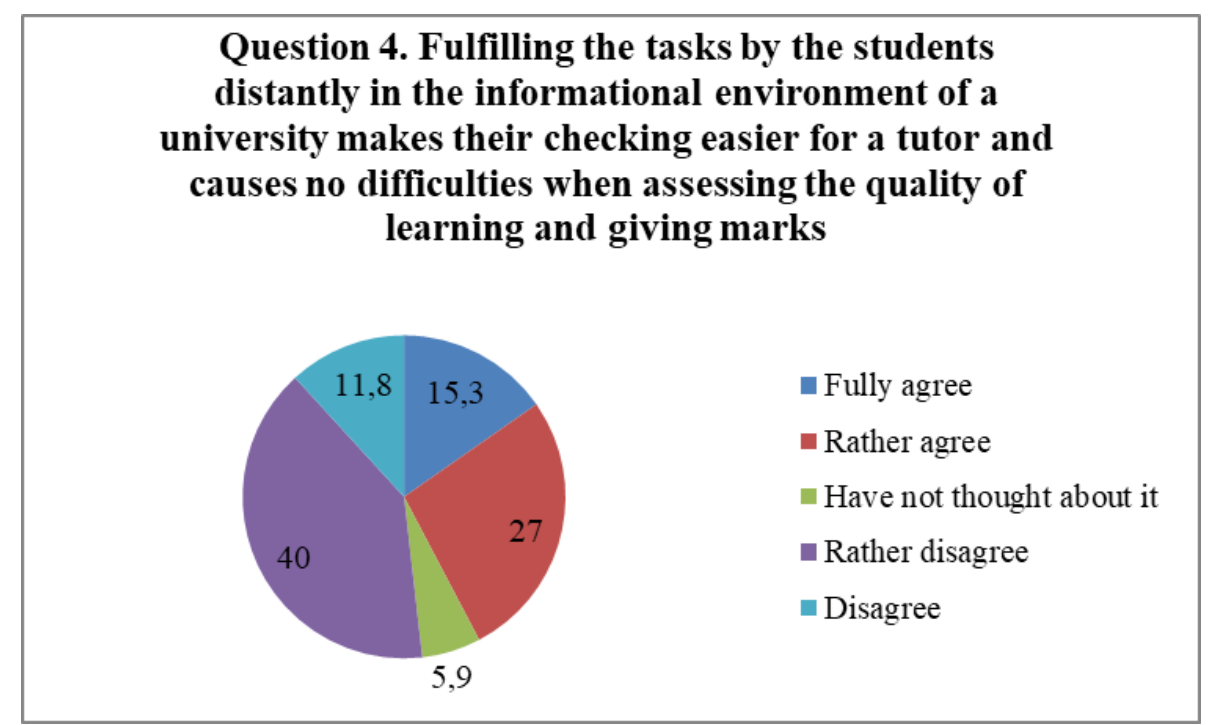

Figure 4. Polling results for question 4

\section{Question 5. There is a psychological problem of professors' lack of readiness for innovations introduced in the informational environment of a university, which decreases the quality of educational process as a whole}

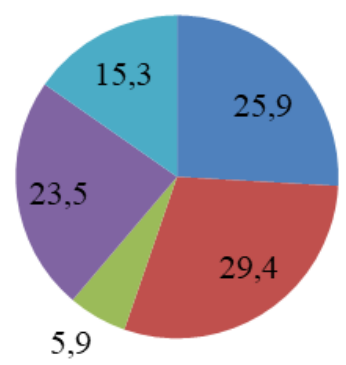

- Fully agree

- Rather agree

- Have not thought about it

- Rather disagree

- Disagree

Figure 5. Polling results for question 5

Below we explain the results of question 2 processing, which present a comparative characteristic of the content quality. While the overall number of answers "I have not thought about it" was rather low (about 6\%), this question was different, as $21.2 \%$ of professors do not think about the comparative characteristic of the material uploaded to the university's teaching (educational) portal for students. At the same time, $60 \%$ of professors $(27.1 \%+32.9 \%)$ generally agree that the comparative characteristic of the content quality must be present, as it reflects the quality of the content in the educational process.

\section{Stage 3. Compiling the Summary Table with Polling Results}

As the research implies quantitative assessment of the responses and calculation of Spearman pair correlation coefficients (with a number of intermediate stages), at this stage the summary tables were compiled using Excel table software. For each question and each professor, a separate table was compiled. An example of question 1 processing is shown in Table 4. As the poll comprised 182 people and the table is large, we present only a fragment of the summary table. 
Table 4. A fragment of polling results for composing the summary table

\begin{tabular}{|c|c|c|c|c|c|c|}
\hline \multirow{2}{*}{ Professor } & \multicolumn{5}{|c|}{ Questions } & \multirow{2}{*}{ Total } \\
\hline & I & II & III & IV & $\mathbf{V}$ & \\
\hline 1 & 5 & 5 & 5 & 5 & 4 & 24 \\
\hline 2 & 5 & 4 & 5 & 2 & 2 & 18 \\
\hline 3 & 5 & 5 & 5 & 5 & 4 & 24 \\
\hline 4 & 4 & 4 & 4 & 2 & 2 & 16 \\
\hline 5 & 4 & 4 & 4 & 4 & 1 & 17 \\
\hline 6 & 5 & 5 & 5 & 5 & 5 & 25 \\
\hline 7 & 5 & 5 & 5 & 4 & 5 & 24 \\
\hline 8 & 4 & 1 & 4 & 4 & 1 & 14 \\
\hline \multicolumn{7}{|l|}{$\ldots$} \\
\hline \multicolumn{7}{|l|}{$\ldots$} \\
\hline 180 & 5 & 4 & 5 & 4 & 4 & 22 \\
\hline 181 & 5 & 5 & 5 & 5 & 5 & 25 \\
\hline 182 & 5 & 4 & 5 & 4 & 4 & 22 \\
\hline Total: & 812 & 651 & 779 & 535 & 595 & 3372 \\
\hline
\end{tabular}

Table 5. A fragment of the conjugate table for question 1

\begin{tabular}{|c|c|c|c|c|c|c|c|}
\hline Professor & $\begin{array}{c}\text { Total points, } \\
\text { S。 } \\
\end{array}$ & $\begin{array}{c}\text { Opinion } \\
\text { points, } S_{b}\end{array}$ & $\begin{array}{l}\text { Difference of } \\
\text { points, } S_{o}-S_{b}\end{array}$ & Ranking, $S_{b}$ & $\begin{array}{c}\text { Ranking of } \\
\text { difference, } S_{o}-S_{b}\end{array}$ & $\begin{array}{c}\text { Difference of } \\
\text { rankings, } d\end{array}$ & $\begin{array}{c}\text { Square difference } \\
\text { of rankings, } d^{2}\end{array}$ \\
\hline 1 & 2 & 3 & 4 & 5 & 6 & 7 & 8 \\
\hline 1 & 24 & 5 & 19 & 55 & 18.5 & 36.5 & 1332.25 \\
\hline 2 & 18 & 5 & 13 & 55 & 114 & -59 & 3481 \\
\hline 3 & 24 & 5 & 19 & 55 & 18.5 & 36.5 & 1332.25 \\
\hline 4 & 16 & 4 & 12 & 137.5 & 128 & 9.5 & 90.25 \\
\hline 5 & 17 & 4 & 13 & 137.5 & 114 & 23.5 & 552.25 \\
\hline 6 & 25 & 5 & 20 & 55 & 4.5 & 50.5 & 2550.25 \\
\hline 7 & 24 & 5 & 19 & 55 & 18.5 & 36.5 & 1332.25 \\
\hline 8 & 14 & 4 & 10 & 137.5 & 147.5 & -10 & 100 \\
\hline \multicolumn{8}{|l|}{$\ldots$} \\
\hline \multicolumn{8}{|l|}{$\ldots$} \\
\hline 180 & 22 & 5 & 17 & 55 & 51 & 4 & 16 \\
\hline 181 & 25 & 5 & 20 & 55 & 4.5 & 50.5 & 2550.25 \\
\hline 182 & 22 & 5 & 17 & 55 & 51 & 4 & 16 \\
\hline Total: & 3372 & 812 & 2560 & & & 0 & 250889 \\
\hline
\end{tabular}

The "Total" line is necessary to check the correctness of the data recording by the number of corresponding assessments (confirmed by the data from Table 2).

\section{Stage 4. Processing the Results using Statistical Methods}

At this stage, it was necessary to obtain preliminary data to calculate the ranking correlation coefficients. To this end, we calculated a series of indicators for each question, with the account of the point obtained for that question. For each question, conjugate tables were built. These tables can be presented so as to be a continuation of the summary table (see Table 4), which shows the initial data (points) of each respondent for each question.

Table 5 shows the conjugate table for question 1.

For questions 2, 3, 4, and 5, the above indicators, shown in columns 3-8 of Table 5, are calculated in the same way.

\section{Stage 5. Calculating the Spearman Ranking Correlation Coefficient}

The Spearman coefficient, calculated separately for each question, shows the strength of relationships between the studied indicators. The methodology of calculation was described in the work (Kvon et al., 2018); thus, the Spearman ranking correlation coefficient $\left(\mathrm{r}_{\mathrm{s}}\right)$ is calculated as follows:

$$
r_{s}=1-\frac{6 \sum d^{2}}{n\left(n^{2}-1\right)}
$$

where: 
Table 6. Results of calculating the ranking correlation coefficients by questions

\begin{tabular}{llc}
\hline $\begin{array}{l}\text { Question } \\
\text { number }\end{array}$ & Wording of the question & $\begin{array}{c}\text { Spearman coefficient } \\
\left(\mathbf{r}_{\mathbf{s}}\right)\end{array}$ \\
\hline Question 1 & $\begin{array}{l}\text { It is necessary to develop a system of motivation of professors to place their materials in } \\
\text { the informational environment of a university and use it in the educational process }\end{array}$ & 0.75 \\
\hline Question 2 & $\begin{array}{l}\text { It is necessary to comparatively assess the quality of the content uploaded to the } \\
\text { informational environment of a university by different professors, as otherwise the } \\
\text { professors would not be motivated for improving it }\end{array}$ & 0.58 \\
\hline Question 3 3 & $\begin{array}{l}\text { It is necessary to protect the materials placed in the informational environment of a } \\
\text { university from their unauthorized use, in order to register the author's contribution to } \\
\text { their development }\end{array}$ & 0.77 \\
\hline Question 4 & $\begin{array}{l}\text { Fulfilling the tasks by the students distantly in the informational environment of a } \\
\text { university makes their checking easier for a tutor and causes no difficulties when } \\
\text { assessing the quality of learning and giving marks }\end{array}$ & 0.43 \\
\hline Question 5 & $\begin{array}{l}\text { There is a psychological problem of professors' unpreparedness for innovations } \\
\text { introduced in the informational environment of a university, which decreases the quality } \\
\text { of the educational process as a whole }\end{array}$ & 0.72 \\
\hline
\end{tabular}

$\mathrm{d}$ - difference of rank pairs for the i-th question (opinion);

$\mathrm{n}$ - number of rank pairs (number of respondents)

The Spearman ranking correlation coefficient enables to statistically determine the presence of correlation between phenomena. Its calculation implies setting an ordinal number for each indicator - a rank, which can be both ascending and descending.

The results of calculating the above coefficients for all questions are shown in Table 6.

The calculation results show an insignificant dispersion of coefficients by the studied questions, but the obtained coefficients demonstrate a high or middle degree of relationship between the two series of the compared quantitative indicators.

\section{Stage 6. Interpretation of the Results}

To analyze the obtained results, we use the boundaries of coefficients which would enable to refer the Spearman coefficients to a certain group. The closer correlation coefficient module to 1, the stronger the relationship between the measured values. When using the ranking correlation coefficient $\left(\mathrm{r}_{\mathrm{s}}\right)$, the strength of the relationship between the following indicators is conditionally estimated:

- the coefficient values less or equal to 0.3 characterize a low strength of relationship;

- values from 0.4 to 0.7 - moderate strength of the relationship,

- values over 0.7 - high strength of the relationship.

The research shows that, according to the calculated coefficients, there are strong relationships in questions 1 , 3 , and 5. This indicator reflects the significance of the questions concerning motivation (and, accordingly, stimulation of the professors for additional workload when working with information technologies $\left(\mathrm{r}_{\mathrm{s}}=0.75\right)$; also, it is worrying that the materials of the professors placed in the informational environment of a university are often not protected from unauthorized use $\left(\mathrm{r}_{\mathrm{s}}=0.77\right)$. The greatest anxiety is caused by the psychological unpreparedness of some professors for working with information technologies $\left(\mathrm{r}_{\mathrm{s}}=0.72\right)$, which leads to a certain counteraction against the inevitable process of introducing innovations into the educational process.

For question 2 and 4, the strength of the relationship is moderate. For example, in question 4, the location of passing the tests is not a very significant factor: in the presence of a tutor (in class) or offline (without tutors). The value of coefficient $r_{s}$, equal to 0.43 , cannot be considered low, as this factor is rather significant; however, its significance is much lower than that of questions 1,3 , and 5 .

\section{DISCUSSIONS}

Implementation of educational activity with the use of information and communication technologies leads to a qualitative change of the conditions and factors of the educational process at a university. The difficulties arising during this process demand taking them into account and reacting promptly.

When carrying out the research, the authors faced certain difficulties; in particular, the question concerning motivation and stimulation of professors when working with information technologies caused difficulties. The works within the informational environment of a university are included in the "extracurricular" workload, thus 
being obligatory and implying no additional stimulation. Despite this, some professors consider the additional stimulation necessary. When developing the questionnaire, we initially considered it necessary to develop a system of motivation of professors to place their materials in the informational environment of a university and use it in the educational process. However, later we excluded it from the analysis. We consider it necessary to continue research on this issue, as this criterion (working with information technologies) is obligatory at many universities. Also, the materials placed in the informational environment of a university are used as a criterion for a professor's ranking but is not stimulated, as a rule.

In the opinion of most professors, working in the informational environment when a student does control tests distantly does not properly reduce their workload, although that was one of the goals initially. In this regard, it is necessary to search for means to optimize the work of professors with the informational environment. A part of professors' functions of placing the content in the informational environment should be transferred to the IT department of the university.

The merit of the present research is its anonymity, as it eliminates the answers expected by an interviewer or a university administration. This enhances the reliability and objectivity of the obtained results.

Another relevant issue is the promotion of professors' qualification. The present research did not touch upon this issue, but taking into account the new conceptions, such as Andragogy, Heutagogy, Paragogy, Peeragogy, and Cybergogy, requires of the teaching staff not only an excellent mastering of their subject but also new skills under the changed approaches to teaching.

Although students still give rather high evaluation of a tutor's role in education (Kvon et al., 2016, 2018), the tutor must very well know the terminology of online learning, understand the fundamentals of the educational platform not only as an educational resource where the teaching materials are placed, but also as a tool for their operative management. Social interaction skills are also required, in both real and virtual environments, which is not adequately perceived and customary for all professors. Some universities organize the appropriate training, but it is usually limited to elaborating certain skills required for working in the specific informational system of the university. However, the problem of adaptation to the virtual environment remains topical for many universities.

\section{CONCLUSION}

Introduction of the educational innovations based on information and communication technologies, providing the development of the educational system to enhance the competitiveness of a university graduate today, leads to transformations of the techniques of the educational process organization.

The objectives set were achieved in the course of the performed research.

As the first objective implied, a questionnaire was developed and polling was carried out among the professors of various universities concerning the problems of working in the informational environment of a university. The polling comprised 182 people; the opinions were assessed by a 5-point interval scale. It should be noted that the questions were initially formulated in such a way that the problem aspects could be comprehended by professors.

Under the second objective, the authors identified the problems impeding the implementation of information and communication technologies at a university; these problems include the lack of motivation system for professors to place their materials in the informational environment of a university. The professors worry that the modern system of digital educational resources does provide protection of copyright, as all materials can be loaded from the university portal by the students and used not for education purposes only. Another problem revealed during the research was the psychological unpreparedness of some professors for working with information technologies and a certain degree of rejection of innovations in education.

Under the third objective, the authors processed the questionnaires and compiled analytical summary tables, to quantitatively characterize the revealed problem aspects. Their significance was measured by using the mathematical tools when processing the interval scales with ranking correlation methods for each question (problem).

Solving the fourth objective based on Spearman coefficients calculation enabled to determine the strength of relationships between the set problems and the efficiency of forming the informational and digital environment of a university. Within the set limit, the authors identified the key problems demanding close attention of the universities' administrations.

Thus, although the expediency of developing the informational and digital environment of a university is apparent, it is necessary to take into account the new pedagogical concepts relevant to the modern social-economic processes, to analyze the emergent problems, and to take into account the interests of professors as the driving force and the main resource of this process. 


\section{ACKNOWLEDGEMENT}

1. The work is performed according to the Russian Government Program of Competitive Growth of Kazan Federal University.

2. The publication has been prepared with the support of the 'RUDN University Program 5-100'.

3. The work is performed according to the project of improving competitiveness of the leading Russian universities among the leading world scientific education centers "5-100" of First Moscow State Medical University.

\section{REFERENCES}

Calvo, M., Carnicer, A., Cuadros, J., Martori, F., Miñarro, A., \& Serrano, V. (2019). Computer-Assisted Assessment in Open-Ended Activities through the Analysis of Traces: A Proof of Concept in Statistics with $\mathrm{R}$ Commander. EURASIA Journal of Mathematics, Science and Technology Education, 15(9), em1743. https://doi.org/10.29333/ejmste/108456

Dubina, I. N. (2006). Mathematical principles of empirical social-economic studies: tutorial. Barnaul: Altay University Publishers, 263. Retrieved on 03 May 2019 from http:/ / lc.kubagro.ru/sei.pdf

Elikanida, P. M., Prokopyev, A. I., Kostyleva, G. V., Blinov, L. V., Fedorov, V. V., \& Polichka, A. E. (2018). Scientific - methodical resource of student training and vocational motivation development in university. ESPACIOS, 39(20), 144-156. Retrieved from http:/ / www.revistaespacios.com/a18v39n20/18392015.html

Gutierrez, K. (2014). 3 Key Concepts That Will Help You Understand Learning in the Digital Age. SHIFT e-Learning. Retrieved from https://www.shiftelearning.com/blog/bid/349245/3-Key-Concepts-That-Will-Help-YouUnderstand-Learning-in-the-Digital-Age

Hsu, Y. C., \& Shiue, Y. M. (2018). Exploring the Influence of Using Collaborative Tools on the Community of Inquiry in an Interdisciplinary Project-based Learning Context. EURASIA Journal of Mathematics, Science and Technology Education, 14(3), 933-945. https:/ / doi.org/10.12973/ ejmste/81149

Kirilova, G. I., Grunis, M. L., Galimova, E. G., \& Kardenas, O. G. (2018). Dynamics of managing the development of the informational environment of educational establishments under competence approach. Kazan Pedagogical Journal, 6, 31-36. Retrieved from https:/ / repository.kpfu.ru/eng/?p_id=193674\&p_lang=2

Kondrateva, I. G., Madyakina, N. Yu., \& Galiullina, E. B. (2018). Open learning technologies: foreign experience. Vestnik NTsBGD, 1(35), 41-47.

Kvon, G. M., \& Vaks, V. B. (2017). Feature of the electronic learning management system in educational process. Conference Proceedings: Education: innovations and traditions (p. 104-105). Prague: WORLD PRESS.

Kvon, G. M., Fatykhova L. I., Vaks, V. B., \& Puris, A. V. (2016). Implementation of innovative solutions in the university educational process. Bulletin of Belgorod University of Cooperation, Economics and Law, 5(61), 244254. https:/ / doi.org/10.21295/2223-5639-2016-5-244-254

Kvon, G. M., Vaks, V. B. \& Pozdeeva, O. G. (2018). Using the Likert scale in the study of students' motivational factors. Scientific and methodical electronic journal "Concept", 11, 84-96. https:// doi.org/10.24411/2304-120X2018-11086

Kvon, G. M., Vaks, V. B., Masalimova, A. R., Kryukova, N. I., Rod, Y. S., Shagieva, R. V., \& Khudzhatov, M. B. (2018). Risk in Implementing New Electronic Management Systems at Universities. EURASIA Journal of Mathematics, Science and Technology Education, 14(3), 891-902. https:/ / doi.org/10.12973/ejmste/81060

Marutsak, L. I. (2015). Processing of data measured in the Likert scale using theory of fuzzy sets. Information technologies in science, management, social sphere, and medicine (p. 880-881). Tomsk: National Research Tomsk Polytechnical University Publishers.

Masalimova, A. R., Vaks, V. B., \& Kvon, G. M. (2018). Implementation of competence-based approach with innovative components of the educational process in university. Scientific and methodical electronic journal "Concept", 9, 116-127. https:/ / doi.org/10.24422/MCITO.2018.9.16656

Modern digital educational environment in the Russian Federation (2016). Priority project. Retrieved on 02 May 2019 from http:/ / neorusedu.ru/about

Munyengabe, S., Mukamusoni, D., Harindintwari, J., \& Ndeze, J. C. (2019). Information Communication Technology as Catalyst for Pedagogical Changes to Generate a Smart Manpower Requirement in Developing Countries. EURASIA Journal of Mathematics, Science and Technology Education, 15(10), em1753. https://doi.org/10.29333/ejmste/109041 
Nadreeva, L. L. (2018). Transformation of the human resources management model in the training discipline "Personnel management" in conditions of transition to the digital economy. Vestnik NTsBGD, 4(38), 20-26.

Nikonorova, L. M., \& Maminiva, L. V. (2018). Potential of modular teaching in the development of learners' selfeducation competence for university students. Vestnik NTsBGD, 4(38), 26-30.

Saygusheva, L. I. (2013). On the issue of innovative educational technologies at a university. Psychology and Pedagogy: methodology and problems of practical application, 30. Retrieved from https://vivliophica.com/articles/education/385354

These are 4 concepts shaping 21 ${ }^{\text {st }}$ Century Learning. (2014). Educational Technology and Mobile Learning. Retrieved from https:/ / www.educatorstechnology.com/2014/12/these-are-4-concepts-shaping-21st.html

\section{http://www.ejmste.com}

